\title{
Changes in SNAI1 and VIM gene expression in Caco2 cells after co-cultivation with bacteria from colorectal cancer biopsies
}

\author{
L. WACHSMANNOVA*, V. STEVURKOVA, S. CIERNIKOVA \\ Department of Genetics, Cancer Research Institute BMC, Slovak Academy of Sciences, Bratislava, Slovakia \\ ${ }^{*}$ Correspondence: exonlmat@savba.sk
}

Received November 20, 2018 / Accepted January 22, 2019

\begin{abstract}
The development of distant metastases is the final stage in the solid cancer progression and it is responsible for the majority of cancer-related deaths. Epithelial-mesenchymal transition (EMT) is involved in cancer progression and metastasis. In the present study, we used different types of intracellular bacteria isolated from colorectal cancer biopsies to examine their effect on the expression of SNAI1 and VIM genes in Caco2 cell line. SNAI1 gene expression was significantly decreased after co-cultivation of Caco2 cells with Pseudomonas aeruginosa, Proteus vulgaris, Proteus mirabilis, Enterococcus faecalis, Klebsiella pneumoniae and Bacillus cereus, respectively $(\mathrm{p}<0.05)$. We observed more than 2 -fold increase in VIM gene expression within $\mathrm{Caco} 2$ cells after co-cultivation with Proteus vulgaris. On the other hand, VIM gene expression decreased by half after co-cultivation with Pseudomonas aeruginosa and Proteus mirabilis $(\mathrm{p}<0.05)$. Our data suggest that bacteria presented in colorectal carcinoma tissues may cause changes in gene expression of EMT-associated genes. Further research is needed to find out whether bacteria are capable to support EMT and cancer progression.
\end{abstract}

Key words: bacteria, metastasis, colorectal cancer, SNAI1, VIM, vimentin, epithelial-mesenchymal transition (EMT)

Colorectal cancer (CRC) is a very common and lethal disease, which is influenced by both environmental and genetic factors. An overwhelming body of evidence has determined the relationship between certain bacteria and particular cancers [1]. The invasion and metastasis of colon cancer cells weakens the effect of the treatment, leading to a high mortality rate. Metastasis is closely related to the biological transformation process where cells gradually lose an epithelial phenotype and obtain a mesenchymal phenotype [2]. This is known as epithelial-mesenchymal transition (EMT). The EMT is a response by the whole organism to generate multiple layers and complex organs during normal development, and it is also a response to pathological conditions such as tumorigenesis, hypoxia, or chronic inflammation $[3,4]$. It is a fundamental process of development and disease progression [5]. The transition from epithelial to mesenchymal states allows a cell to break away from its originating tissue and travel throughout the body. EMT is induced during activation of numerous signaling mechanisms and is regulated by several pathways. Some of the EMT-signaling pathways are upregulated by microbial pathogens, which suggests that pathogens may also be EMT inducers [6].

One of the most distinguishing features of the EMT phenotype establishment is the upregulated expression of mesenchymal markers [7]. One of these mesenchymal markers is Vimentin gene (VIM), which encodes highly conserved protein $(53 \mathrm{kDa})$ that belongs to the type III intermediate filament family [8]. Vimentin is a multifunctional protein, responsible for maintaining cell shape, cytoplasm integrity, stabilizing cytoskeletal interactions, and it is also involved in the immune response [9]. Several Gram-negative pathogens such as the Enterobacteriaceae have been found to interact with vimentin both inside and on the eukaryotic cell surface $[10,11]$. Hofman and Vouret-Craviari [6] speculate that most microbes that persist in the body have the potential to indirectly favor an EMT behavior.

VIM expression is altered by EMT-initiating transcription factors - SNAI1 (Snail1) and SNAI2 (Snail2). These transcriptions factors belong to a large superfamily known as SNAI and participate in cell differentiation and survival [12]. In the members of this family, the C-terminal domain is highly conserved in contrast to the divergent $\mathrm{N}$-terminal region [13]. The C-terminal DNA-binding domain region of Snaill and Snail2 differs in the zinc finger number: four (ZF1 to ZF4) in Snail1 and five (ZF 1 to ZF5) in Snail2. This difference might account for the differential interactions and/or binding affinities to target genes [14]. Snail2 expression is increased in patients with melanoma, lung, colon and 
ovarian cancer [15]. Snail1 and Snail2 are linked to tumor progression and invasiveness by their ability to alter VIM expression $[16,17]$.

In the present study, we mainly focus on altered expression of two genes associated with EMT in human adenocarcinoma cell line Caco2 after co-cultivation with bacteria isolated from colorectal biopsies [18]. We used different types of intracellular bacteria to examine their effect on the SNAI1 and VIM expression, and evaluated the possible role of these bacteria on cancer progression and metastasis.

\section{Materials and methods}

Cell culture. The human adenocarcinoma cell line Caco2 was maintained and cultured in high-glucose $(4.5 \mathrm{mg} / \mathrm{ml})$ DMEM (Biochrom AG, Berlin, Germany) supplemented with $10 \%$ fetal bovine serum (FS) (Biochrom AG), an antibiotic/antimycotic mix (10000 IU/ml penicillin; $5 \mu \mathrm{g} / \mathrm{ml}$ streptomycin; $2.5 \mu \mathrm{g} / \mathrm{ml}$ amphotericin) and $2 \mathrm{mM}$ glutamine. The cells were maintained in a humidified atmosphere at $37^{\circ} \mathrm{C}$ and $5 \% \mathrm{CO}_{2}$. All the chemicals were purchased from SigmaAldrich (St Louis, MO, USA) if not stated otherwise.

Bacteria isolates. Bacteria obtained in our previous study were used for co-cultivation with $\mathrm{Caco} 2$ cell lines. Intestinal bacteria of CRC patients were isolated from colorectal biopsies using gentamycin protection assay [18] and maintained and cultured in LB medium. In this experiment, we used Klebsiella pneumoniae, Proteus vulgaris, Proteus mirabilis, Pseudomonas aeruginosa, Enterococcus faecalis and Bacillus cereus.

Co-cultivation. $\mathrm{CaCo} 2$ cells were seeded at a density of $5 \times 10^{6} \mathrm{cell} /$ Petri dish and incubated at $37^{\circ} \mathrm{C}$ until a confluent monolayer formed, followed by PBS washing. Each monolayer was infected with approximately $5 \times 10^{7}$ bacteria in a culture medium without antibiotics. After 3 hours of incubation at $37^{\circ} \mathrm{C}$, the monolayer was washed with PBS. To eliminate all extracellular bacteria, the $\mathrm{CaCo} 2$ cells were treated with DMEM which contained gentamicin $(100 \mu \mathrm{l} / \mathrm{ml})$. After 1-hour incubation, the cells were washed 2 times with PBS and cultured for 48 hours at $37^{\circ} \mathrm{C}$ in $5 \% \mathrm{CO}_{2}$.

RNA isolation and cDNA synthesis. Total RNA was extracted from $5 \times 10^{5}$ cultured cells using the NucleoSpin

Table 1. List of primers.

\begin{tabular}{llcc}
\hline $\begin{array}{l}\text { Oligo } \\
\text { name }\end{array}$ & Sequence $\left(\mathbf{5}^{\prime} \rightarrow \mathbf{3}^{\prime}\right)$ & Length & $\begin{array}{c}\text { Amplicon } \\
(\mathbf{b p})\end{array}$ \\
\hline GAPDH-F & GAAGGTGAAGGTCGGAGTC & 19 & 226 \\
GAPDH-R & GAAGATGGTGATGGGATTTC & 20 & \\
Snaill-F & CAACTGCAAATACTGCAACAAGG & 23 & 245 \\
Snail1-R & ACTTCTTGACATCTGAGTGGGTC & 23 & \\
Snail2-F & CTTTTTCTTGCCCTCACTGC & 20 & 224 \\
Snail2-R & GCTTCGGAGTGAAGAAATGC & 20 & \\
Vimentin-F & CAGGGCGCGTCCTCTGCC & 18 & 228 \\
Vimentin-R & TGGACATGGCTGCGGAGGGT & 20 & \\
\hline
\end{tabular}

RNA II kit (Macherey-Nagel, Dueren, Germany). RNA was depleted from genomic DNA by DNase treatment (RapidOut DNA Removal Kit; Thermo Fisher Scientific, Waltham, MA, USA). The light absorbance at 260 and $280 \mathrm{~nm}$ was measured by NanoDrop 1000 Spectrophotometer (Thermo Fisher Scientific). The RNA samples with optimum A260/A280 ratio were selected to synthesize complementary DNA. $1 \mu \mathrm{g}$ of total RNA was reverse transcribed using SensiFAST cDNA Synthesis Kit (Bioline, London, UK). Reaction volume was $20 \mu \mathrm{l}$ including: total RNA $(1 \mu \mathrm{g}), 5 \times$ TransAmp Buffer $(4 \mu \mathrm{l})$, Reverse Transcriptase $(1 \mu \mathrm{l})$ and DNase/RNase free-water (up to $20 \mu \mathrm{l}$ ). Then the samples were incubated for $10 \mathrm{~min}$ at $25^{\circ} \mathrm{C}, 15 \mathrm{~min}$ at $42^{\circ} \mathrm{C}$ and $5 \mathrm{~min}$ at $85^{\circ} \mathrm{C}$.

Primers. Snail1, Snail2 and Vimentin genes were selected as a target and Glyceraldehyde-3-phosphate dehydrogenase $(\mathrm{GAPDH})$ gene was chosen as a reference gene. Oligonucleotide sequences are listed in Table 1.

Quantitative Real-Time PCR analysis. Qualitative RT-PCR was performed in triplicates in $1 \times \mathrm{GoTaq}^{\circledR} \mathrm{qPCR}$ Master Mix, $0.25 \mathrm{pmol} / \mu \mathrm{l}$ concentration of primers and $0.5 \mu \mathrm{l}$ template cDNA per one reaction. The protocol for RT-qPCR started with the activation step at $95^{\circ} \mathrm{C}$ for $2 \mathrm{~min}$, followed by 40 cycles which consisted of three steps: $15 \mathrm{sec}$ at $95^{\circ} \mathrm{C}$ for denaturation, $1 \mathrm{~min}$ at $60^{\circ} \mathrm{C}$ for primer annealing and $5 \mathrm{sec}$ at $75^{\circ} \mathrm{C}$ for extension. PCR was performed in Bio-Rad 96FX cycler (Bio-Rad Laboratories, Hercules, CA, USA) and the results were analyzed by Bio-Rad CFX Manager software version 1.6. The gene for glyceraldehyde3 -phosphate dehydrogenase (GAPDH) was used as a reference gene. The sequences of primers for selected genes are listed in Table 1.

The amplification efficiency for the target and reference genes was validated using a 2 -fold dilution series of the cDNA template. A standard curve was drawn by plotting the logarithmic input cDNA concentration versus mean Threshold Cycle (CT) and the slope was determined. PCR efficiency was calculated using the formula: $\mathrm{E}=10^{-1 / \text { slope }}-1$. The relative quantification (RQ) of the gene expression was calculated using formula: $\mathrm{RQ}=2^{-\Delta \Delta \mathrm{Ct}}$ and $\Delta \Delta \mathrm{Cq}=\Delta \mathrm{Cq}$ (TAR) $-\triangle \mathrm{Cq}(\mathrm{REF})$.

Statistics. Relative Expression Software Tool (REST, version 2009) was used for statistical evaluation.

\section{Results}

In our study, we used relative quantification to analyze the changes in gene expression in Caco2 cells affected with bacteria relative to an unaffected control. We used six different types of bacteria isolated from colorectal biopsies for co-cultivation: $P$. aeruginosa, $P$. vulgaris, $P$. mirabilis, $E$. faecalis, $K$. pneumoniae and B. cereus. Relative quantification describes the change in target gene expression relative to reference group such as an untreated control.

The slope of the standard curves for the VIM, SNAI1 and GAPDH genes was $-3.4,-3.27$ and -3.28 , respectively (Figure 


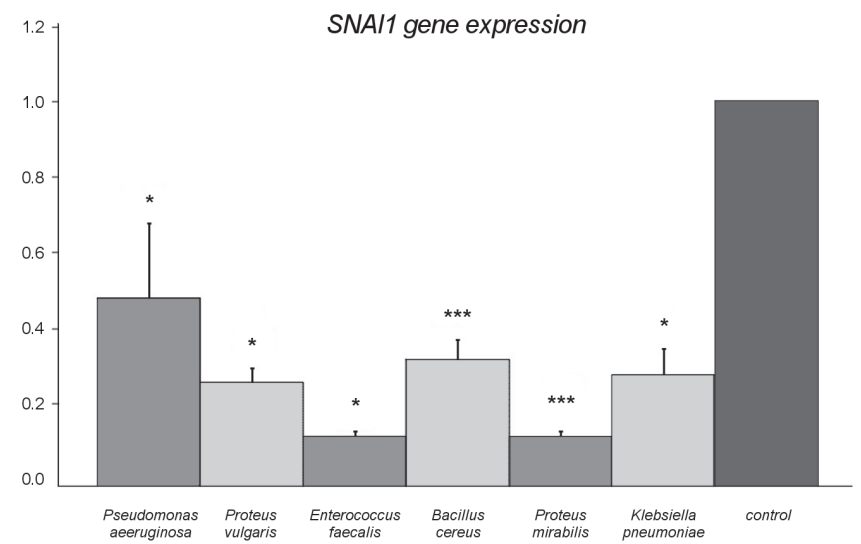

Figure 1. SNAI1 expression in Caco2 cells affected with different types of bacteria isolated from colorectal biopsies. ${ }^{\star * *} \mathrm{p}<0.001,{ }^{*} \mathrm{p}<0.05$; $\mathrm{p}$-values in comparison to control.

S1). The PCR efficiency (E) was $96.9 \%$ for VIM, $102.3 \%$ for SNAI1 and $101.6 \%$ for GAPDH.

Quantitative analysis showed downregulation of SNAI1 expression in all affected cells (Figure 1). SNAI1 gene expression was significantly decreased $(\mathrm{p}<0.05)$. Notably, gene expression decreased significantly in $\mathrm{Caco} 2$ cells affected with E. faecalis and P. mirabilis, SNAI1, approximately 10-fold $(\mathrm{p}<0.001)$. Data analysis showed reduced SNAI1 gene expression by more than a half in $\mathrm{Caco} 2$ cells after co-cultivation with $P$. aeruginosa, $P$. vulgaris, $K$. pneumoniae and $B$. cereus.

Vimentin has higher gene expression pattern in affected Caco2 cells than SNAI1 (Figure 2). Quantitative results have shown that VIM gene expression is increased more than 2 -fold after co-cultivation with P. vulgaris, K. pneumoniae and $B$. cereus, but this increase was significant only for $P$. vulgaris $(\mathrm{p}=0.05)$. VIM gene expression decreased by half in Caco2 cell affected with $P$. aeruginosa and $P$. mirabilis $(\mathrm{p}<0.05)$.

\section{Discussion}

Gut microbiota has been proved to be involved in the initiation and progression of CRC in many ways [19]. The structural difference observed in the fecal microbiota community of CRC patients was related with the non-cancerous population, and some microbiota belonging to the genera of Enterococcus, Escherichia/Shigella, Klebsiella, Streptococcus, and Peptostreptococcus were richer in CRC patients [20]. Bacterial adhesion and invasion might perpetuate the inflammatory response, eg. Streptococcus bovis wallextracted antigens promote carcinogenesis in $\mathrm{CaCo} 2$ cells by over-expression of cyclo-oxygenase 2 [21]. Enterotoxigenic Bacteroides fragilis has induced tumor growth in mice by upregulation of the inflammatory chemokines, interleukin 17 and interleukin 23 [22].

The role of bacteria in cancer progression via EMT signaling pathway has not been studied sufficiently so far. In

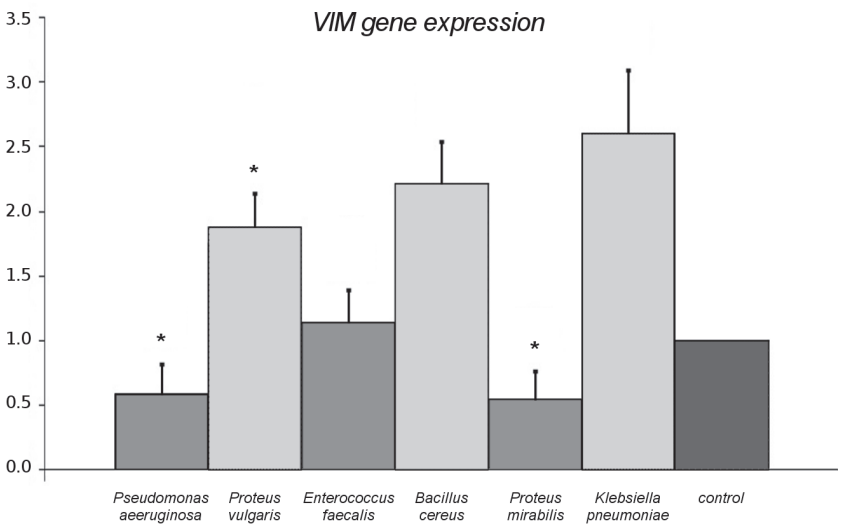

Figure 2. VIM expression in Caco2 cells affected with different types of bacteria isolated from colorectal biopsies. ${ }^{*} \mathrm{p}<0.05$; $\mathrm{p}$-values in comparison to control.

our experiment, we have selected two EMT-associated genes (SNAI1 and VIM) and monitored changes in their expression induced by short co-cultivation of $\mathrm{Caco} 2$ cells with certain bacteria. $\mathrm{CaCo} 2$ cell line is derived from large intestine carcinoma (stage $\mathrm{X}$, grade II) with decreased VIM expression [23]. The results show significantly reduced expression of the SNAI1 gene in Caco2 cells after co-cultivation with all types of bacteria which we used. Similar results were obtained by monitoring the SNAI2 gene expression (not published), but these results were not significant because the level of expression was very low. This can be a reaction of cells to the bacterial attack, since inhibition of Snail1 expression downregulation led to inhibition of the bacterial translocation across the epithelium [24].

Many studies and investigators reported that in majority of the cancers VIM gene expression is varied and revealed an association between their expression and cancer aggressiveness [25-28]. It seems that vimentin expression is not only a marker associated with invasive phenotype but required for carcinoma cell motility. Notably, 70\% inhibition of vimentin expression was sufficient to impair migration and invasion [25].

One possible mechanism for bacteria to influence the carcinogenesis progression could be their involvement in the regulation of vimentin expression. We have detected both increased and decreased expression according to particular bacteria used for co-cultivation. P. mirabilis caused decreased expression of both VIM and SNAI1. This observation may indicate its protective effect in the tumorigenesis process, which has been suggested in several studies. Already in 1965, Toyoichiro et al. [29] reported that P. mirabilis RMS-203 (Murata strain) possessed oncolytic effects in murine tumors. Zhang et al. [30] in their study evaluated the suppressive effect of $P$. mirabilis on breast cancer growth and metastasis in vitro and in vivo. Results showed that $P$. mirabilis could adhere to cells and inhibit cell growth in a non-specific way in vitro, preferentially accumulate in tumor tissues and can markedly 
suppress both tumor growth and pulmonary metastasis in a mouse breast cancer model. $P$. aeruginosa caused decreased expression of both VIM and SNAI1. Borthwick et al. [31] reported no effect on EMT marker expression compared to control in co-cultured cells with $P$. aeruginosa-activated THP-1 cells. $P$. aeruginosa did not drive EMT directly but could accentuate TGF- $\beta 1$ driven EMT indirectly via activation of innate immune cells [31].

In our observations, $K$. pneumoniae upregulated expression of vimentin more than twice, but this increase was not significant. Leone et al. [32] described changes in production of the intracellular reactive oxygen species in cells exposed to K. pneumoniae. The ROS (reactive oxygen species) production is connected to VIM expression, i.e. VIM expression is upregulated by ROS [33]. This can be a possible mechanism by which K. pneumoniae upregulate VIM expression. Similarly, another intracellular bacterium leading to pulmonary infections $M$. tuberculosis induced upregulation of the vimentin expression in human monocytes [34]. Vimentin may be a key regulator of several tumorigenic pathways, as it forms a complex with 14-3-3 that may prevent dephosphorylation of proteins in the complex, thereby inhibiting antitumor activity within the cells. Vimentin has been shown to be required for maturation of invadopodia and to mediate cellular migration and formation of lamellipodia [35].

As we can see from our results, as well as from literature, the ability of some bacterial pathogens to activate EMT is a consequence of the local chronic inflammatory response persistence or depends on a direct interaction of the pathogens with the host epithelial cells. Interestingly, only a short co-cultivation was sufficient to invade cells and influence the level of gene expression. Further research is needed to better define the signaling pathways activated during the early phases of interactions between the bacterium and the host cells. Herein, we have shown that most pathogenic bacteria associated with CRC increased the VIM expression. Vimentin might be a relevant target for cancer therapeutic intervention and has immense potential in terms of novel clinical prognostic and diagnostic tools.

Supplementary information is available in the online version of the paper.

Acknowledgements: This article was prepared with the kind support of the grant VEGA 2/0099/17. The experiments were enabled with the financial support of the RLF2009 and RLF2017 programs founded by the Cancer Research Foundation. We thank the entire Department of Gastroenterology at the National Cancer Institute, Bratislava, Slovakia, for collecting colorectal biopsies.

\section{References}

[1] MAGER DL. Bacteria and cancer: cause, coincidence or cure? A review. J Transl Med 2006; 4: 14. https://doi. org/10.1186/1479-5876-4-14
[2] CHEN T, YOU Y, JIANG H, WANG ZZ. Epithelial-mesenchymal transition (EMT): A biological process in the development, stem cell differentiation, and tumorigenesis. J Cell Physiol 2017; 232: 3261-3272. https://doi.org/10.1002/ jcp. 25797

[3] ANSIEAU S, BASTID J, DOREAU A, MOREL AP, BOUCHET BP et al. Induction of EMT by twist proteins as a collateral effect of tumor-promoting inactivation of premature senescence. Cancer Cell 2008; 14: 79-89. https://doi. org/10.1016/j.ccr.2008.06.005

[4] WU Y, DENG J, RYCHAHOU PG, QIU S, EVERS BM et al. Stabilization of snail by NF-kappaB is required for inflammation-induced cell migration and invasion. Cancer Cell 2009; 15: 416-428. https://doi.org/10.1016/j.ccr.2009.03.016

[5] NAKAYA Y, SHENG G. EMT in developmental morphogenesis. Cancer Lett 2013; 341: 9-15. https://doi.org/10.1016/j. canlet.2013.02.037

[6] HOFMAN P, VOURET-CRAVIARI V. Microbes-induced EMT at the crossroad of inflammation and cancer. Gut Microbes 2012; 3: 176-185. https://doi.org/10.4161/gmic.20288

[7] MICALIZZI DS, FORD HL. Epithelial-mesenchymal transition in development and cancer. Future Oncol 2009; 5: 11291143. https://doi.org/10.2217/fon.09.94

[8] SATELLI A, LI S. Vimentin in cancer and its potential as a molecular target for cancer therapy. Cell Mol Life Sci 2011; 68: 3033-3346. https://doi.org/10.1007/s00018-011-0735-1

[9] OGRODNIK M, SALMONOWICZ H, BROWN R, TURKOWSKA J, SREDNIAWA W et al. Dynamic JUNQ inclusion bodies are asymmetrically inherited in mammalian cell lines through the asymmetric partitioning of vimentin. Proc Natl Acad Sci U S A 2014; 111: 8049-8054. https://doi. org/10.1073/pnas.1324035111

[10] ZOU Y, HE L, HUANG SH. Identification of a surface protein on human brain microvascular endothelial cells as vimentin interacting with Escherichia coli invasion protein IbeA. Biochem Biophys Res Commun 2006; 351: 625-630. https://doi.org/10.1016/j.bbrc.2006.10.091

[11] CHI F, BO T, WU CH, JONG A, HUANG SH. Vimentin and PSF act in concert to regulate IbeA+ E. coli K1 induced activation and nuclear translocation of NF- $\kappa \mathrm{B}$ in human brain endothelial cells. PLoS One 2012; 7: e35862. https:// doi.org/10.1371/journal.pone.0035862

[12] NIETO MA. The snail superfamily of zinc-finger transcription factors. Nat Rev Mol Cell Biol 2002; 3: 155-166. https:// doi.org/10.1038/nrm757

[13] BARRALLO-GIMENO A, NIETO MA. Evolutionary history of the Snail/Scratch superfamily. Trends Genet 2009; 25: 248-252. https://doi.org/10.1016/j.tig.2009.04.001

[14] VILLAREJO A, CORTES-CABRERA A, MOLINA-ORTIZ P, PORTILLO F, CANO A. Differential role of Snaill and Snail2 zinc fingers in E-cadherin repression and epithelial to mesenchymal transition. J Biol Chem 2014; 289: 930-941. https://doi.org/10.1074/jbc.M113.528026

[15] ELLOUL S, ELSTRAND MB, NESLAND JM, TROPE CG, KVALHEIM G et al. Snail, Slug, and Smad-interacting protein 1 as novel parameters of disease aggressiveness in metastatic ovarian and breast carcinoma. Cancer 2005; 103: 1631-1643. https://doi.org/10.1002/cncr.20946 
[16] COME C, ARNOUX V, BIBEAU F, SAVAGNER P. Roles of the transcription factors snail and slug during mammary morphogenesis and breast carcinoma progression. J Mammary Gland Biol Neoplasia 2004; 9: 183-193. https://doi. org/10.1023/B:JOMG.0000037161.91969.de

[17] LEE MY, CHOU CY, TANG MJ, SHEN MR. Epithelialmesenchymal transition in cervical cancer: correlation with tumor progression, epidermal growth factor receptor overexpression, and snail up-regulation. Clin. Cancer Res 2008; 14: 4743-4750. https://doi.org/10.1158/1078-0432.CCR-080234

[18] WACHSMANNOVA L, MAJEK J, ZAJAC V, STEVURKOVA V, CIERNIKOVA S. The study of bacteria in biopsies from Slovak colorectal adenoma and carcinoma patients. Neoplasma 2018; 65: 644-648. https://doi. org/10.4149/neo_2018_1801174N34

[19] CIERNIKOVA S, MEGO M, HAINOVA K, ADAMCIKOVA Z, STEVURKOVA V et al. Modification of microflora imbalance: future directions for prevention and treatment of colorectal cancer? Neoplasma 2015; 62: 345-352. https://doi. org/10.4149/neo_2015_042

[20] WANG T, CAI G, QIU Y, FEI N, ZHANG M et al: Structural segregation of gut microbiota between colorectal cancer patients and healthy volunteers. ISME J 2012; 6: 320-329. https://doi.org/10.1038/ismej.2011.109

[21] BIARC J, NGUYEN IS, PINI A, GOSSÉ F, RICHERT S et al. Carcinogenic properties of proteins with pro-inflammatory activity from Streptococcus infantarius (formerly S.bovis). Carcinogenesis 2004; 25:1477-1484. https://doi.org/10.1093/ carcin/bgh091

[22] WU S, RHEE KJ, ALBESIANO E, RABIZADEH S, WU X et al. A human colonic commensal promotes colon tumorigenesis via activation of $\mathrm{T}$ helper type $17 \mathrm{~T}$ cell responses. Nat Med 2009; 15: 1016-1022. https://doi.org/10.1038/ nm.2015

[23] NIKNAMI Z, ESLAMIFAR A, EMAMIRAZAVI A, EBRAHIMI A, SHIRKOOHI R. The association of vimentin and fibronectin gene expression with epithelial-mesenchymal transition and tumor malignancy in colorectal carcinoma. EXCLI J 2017; 16: 1009-1017. https://doi.org/10.17179/excli2017-481

[24] CLARKE TB, FRANCELLA N, HUEGEL A, WEISER JN. Invasive bacterial pathogens exploit TLR-mediated downregulation of tight junction components to facilitate translocation across the epithelium. Cell Host Microbe 2011; 9: 404-414. https://doi.org/10.1016/j.chom.2011.04.012
[25] MCINROY L, MAATTA A. Down-regulation of vimentin expression inhibits carcinoma cell migration and adhesion. Biochem Biophys Res Commun 2007; 360: 109-114. https:// doi.org/10.1016/j.bbrc.2007.06.036

[26] NGAN CY, YAMAMOTO H, SESHIMO I, TSUJINO T, MAN-I M et al. Quantitative evaluation of vimentin expression in tumour stroma of colorectal cancer. Br J Cancer 2007; 96: 986-992. https://doi.org/10.1038/sj.bjc.6603651

[27] SETHI S, MACOSKA J, CHEN W, SARKAR FH. Molecular signature of epithelial-mesenchymal transition (EMT) in human prostate cancer bone metastasis. Am J Transl Res 2010; 3: 90-99.

[28] WILLIAMS AA, HIGGINS JP, ZHAO H, LJUNBERG B, BROOKS JD. CD 9 and vimentin distinguish clear cell from chromophobe renal cell carcinoma. BMC Clin Pathol 2009; 9: 9. https://doi.org/10.1186/1472-6890-9-9

[29] MURATA T, ARAKAWA M, SUGIYA Y, INAZU Y, HATTORI Z et al. Oncolytic effect of Proteus mirabilis upon tumor bearing animal. Life Sci 1965; 4: 1055-1067.

[30] ZHANG H, DIAO H, JIA L, YUAN Y, THAMM DH et al. Proteus mirabilis inhibits cancer growth and pulmonary metastasis in a mouse breast cancer model. PLoS One 2017; 12 : e0188960. https://doi.org/10.1371/journal.pone.0188960

[31] BORTHWICK LA, SUNNY SS, OLIPHANT V, PERRY J, BRODLIE $M$ et al. Pseudomonas aeruginosa accentuates epithelial-to-mesenchymal transition in the airway. Eur Respir J 2011; 37: 1237-1247. https://doi. org/10.1183/09031936.00088410

[32] LEONE L, MAZZETTA F, MARTINELLI D, VALENTE $\mathrm{S}$, ALIMANDI $\mathrm{M}$ et al. Klebsiella pneumoniae Is Able to Trigger Epithelial-Mesenchymal Transition Process in Cultured Airway Epithelial Cells. PLoS One 2016; 11: e0146365. https://doi.org/10.1371/journal.pone.0146365

[33] MAHESH PP, RETNAKUMAR RJ, MUNDAYOOR S. Downregulation of vimentin in macrophages infected with live Mycobacterium tuberculosis is mediated by Reactive Oxygen Species. Sci Rep 2016; 6: 21526. https://doi. org/10.1038/srep21526

[34] GARG A, BARNES PF, PORGADOR A, ROY S, WU S et al. Vimentin expressed on Mycobacterium tuberculosisinfected human monocytes is involved in binding to the NKp46 receptor. J Immunol 2006; 177: 6192-6198. https:// doi.org/10.4049/jimmunol.177.9.6192

[35] KIDD ME, SHUMAKER DK, RIDGE KM. The Role of Vimentin Intermediate Filaments in the Progression of Lung Cancer. Am J Respir Cell Mol Biol 2014; 50: 1-6. https://doi. org/10.1165/rcmb.2013-0314TR 